\title{
Electrodeposition of noble metals nanoparticles on carbon nanotubes
}

Bernadette M. Quinn, Cees Dekker, Serge G. Lemay

Kavli Institute of Nanoscience, Delft University of Technology, Lorentzweg 1, 2628 CJ Delft, The

Netherlands

\section{SUPPORTING INFORMATION}

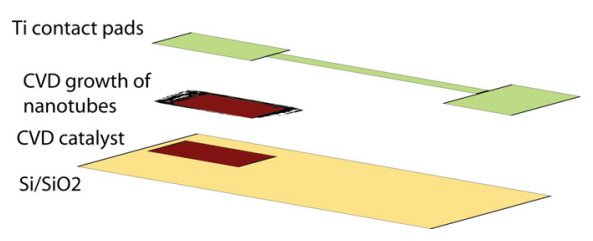

Figure S1 Schematic illustration of steps involved in the fabrication of nanotube array devices

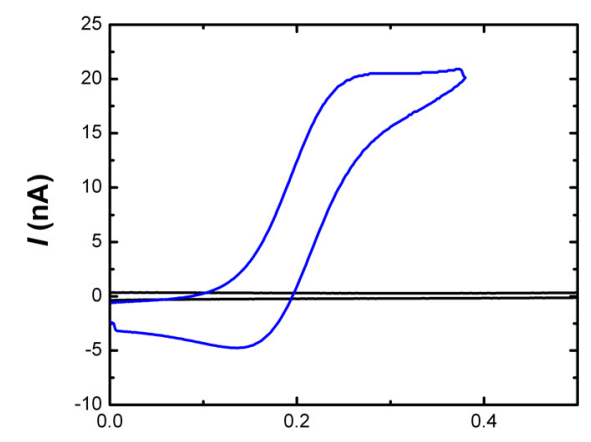

Figure S2 Typical cyclic voltammogram (CV) at SWNT array device (blue line) in the presence of 1 $\mathrm{mM}$ ferrocene methanol compared with that for an identical device without the SWNTs (black line). Scan rate $100 \mathrm{mV} \mathrm{s}^{-1}$, base electrolyte $100 \mathrm{mM} \mathrm{KCl}$

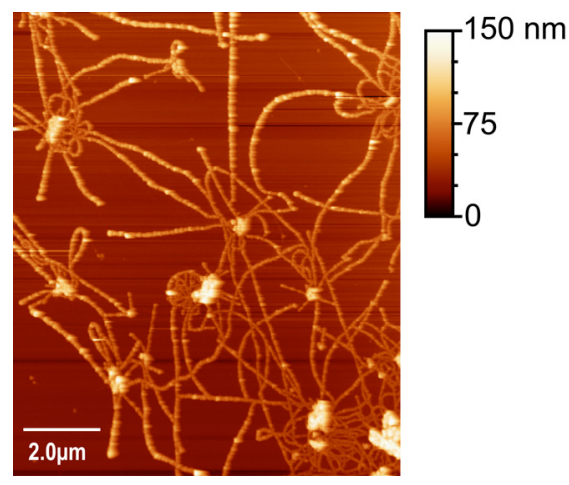

Figure $\mathbf{S 3}$ Tapping mode AFM image in air of SWNTs post $\mathrm{Pd}$ electrodeposition $(0.2 \mathrm{mM}$ $\left(\mathrm{NH}_{4}\right)_{2} \mathrm{PdCl}_{4}+100 \mathrm{mM} \mathrm{KCl}, E_{\mathrm{n}}=-1.5 \mathrm{~V}$ vs. $\mathrm{Ag} / \mathrm{AgCl}$, deposition time $2.5 \mathrm{~s}$ ). The tubes visible in the image are located far from the Ti contact wire perimeter $(>10 \mu \mathrm{m})$ and are electrically connected via 2 or 3 nanotubes that were sufficiently long to physically contact the $\mathrm{Ti}$ wire. All tubes were equally plated. 

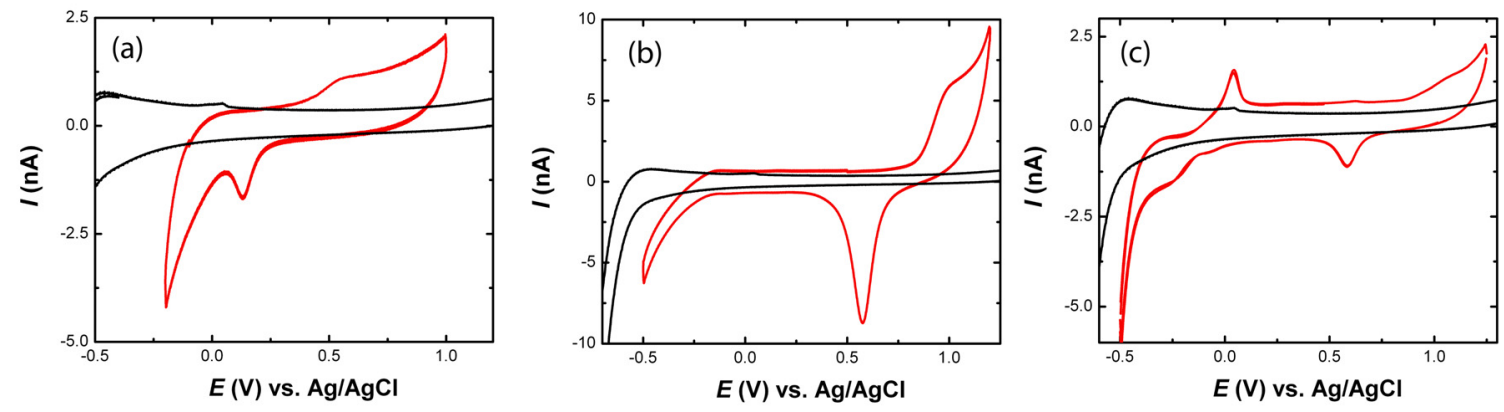

Figure 4 CVs of SWNT arrays post (a) $\mathrm{Pd}$ (b) $\mathrm{Pt}$ and (c) Au deposition in $0.1 \mathrm{M} \mathrm{H}_{2} \mathrm{SO}_{4}$ (red line). The response from the metal nanoparticle coated array is compared with the response from a bare SWNT array (black line). Scan rate $100 \mathrm{mV} \mathrm{s}^{-1}$.

\section{Complete reference citation for ref 12}

(12) Stadermann, M.; Papadakis, S. J.; Falvo, M. R.; Novak, J.; Snow, E.; Fu, Q.; Liu, J.; Fridman, Y.; Boland, J. J.; Superfine, R.; Washburn, S. Phys. Rev. B 2004, 69, 201402 . 